\title{
Maximizing Technology Use in Early Childhood Settings: Leadership Strategies
}

\author{
Christina C. W. Han \\ Hong Kong Institute of Education \\ Hong Kong
}

\begin{abstract}
Effectively use of technologies in early childhood centres has influential impact on learning and teaching. Leaders of early childhood centres have crucial roles to promote the good use of learning technologies . In Hong Kong, with millions of dollars subsidies from the SAR government to early childhood centres for improving early childhood quality under the Voucher scheme since 2007. Many more early childhood leaders equip their centres with different kinds of new technologies. However, the usage rate of technologies in early childhood classrooms is relatively low compare with other teaching and learning facilities. In this study, I aim to investigate the leadership strategies applied by leaders to promote technology use in early childhood centres. Case study was applied to investigate the leadership strategies, in-depth interview were conducted with principal and teachers in a well-resourced digitized kindergarten in Hong Kong. Thematic analysis was applied to draw the findings. Major findings on leadership strategies include: providing authentic support, encouraging active trial, leading practical practice and forming pro-digital culture in organization.
\end{abstract}

\section{Introduction}

Using technologies for learning in early childhood centers is getting common nowadays. Many early childhood centers are equipped with laptop computers, smart books, tablets and electronic toys. Some resourceful centers have digital whiteboards for teaching and learning uses as well. However, to equip the centers with all digital technologies does not mean the technology facilities have been applied effectively in classrooms. Leaders play an influential role to lead innovation and technological change in schools [1]; [7]; [16]. Leadership behaviours of school leaders affect the success or failure of technology implementation [15]. In Hong Kong, with millions of dollars subsidies from the SAR government to early childhood organizations for improving early childhood quality under the Voucher scheme since 2007 [9]. Many early childhood leaders purchased digital learning technologies but the usage rate of technologies are relatively low compare with other teaching and learning facilities [11]. In addition, many early childhood leaders complain that they lack the technical skills in using computer and strategies to promote effective use of technologies for learning [12]. It is problematic for school leaders to promote technologies if they do not feel confident in dealing with technologies themselves [5]. In this study, I aim to investigate the leadership strategies used by a leader who works in a well resourced early childhood center, and the centre has won an outstanding quality school award. The findings are useful for those early childhood centre leaders who want to promote the improvement of applying technologies in advancing school quality.

\section{Leadership and technologies}

Unquestionably, technology plays a crucial role in impacting teaching practices and children's learning within and outside schools [4]. To introduce technologies in early childhood settings, school leaders need to be equipped for it. Recent research indicates that school leaders who want to enhance technologies use in schools need to instruct teachers on particular skills for learning about technologies and lead staff through appropriate daily practice [13]; [17]. Leaders are also expected to provide access to technologies resources and support teachers for technologies use. In addition, school leaders are expected to collaborate with teachers in the development of learning materials for classroom usage [18]. Therefore, school leaders are playing important roles in promoting technolgoies use in education settings. Research also stresses that leadership of school leaders is essential for effective technologies integration [1]; [3].

Furthermore, according to Schmeltzer, effective school leaders need to be capable not only in basic technologies competencies such as word processing, email, and internet search, but also in understanding how technologies can improve instructional practices, and in developing strategies for helping teachers use technologies in their classrooms [17]. In addition, strong team-building and mentoring skills are required to create a system of on-going 
support for the whole school as it applies technologies.

Consistent with Schmeltzer [17], Anderson and Dexter [1] stress that school technologies leaders not only need to be competent in technologies use themselves, but also need to pay crucial attention in setting up technology team and policy, and providing support to teachers for effective technology implementation.

The International Society for Technology in Education (ISTE) in the United States reviewed the National Education technology Standards for Administrators (NETS*A) in 2009. It outlines the essential technology requirements and issues for school administrators in United States as follows:

- Visionary leadership: inspire and facilitate among all stakeholders, implement technology-infused strategic plans aligned with a shared vision, and advocate policies, programmes and funding

- Digital-Age learning culture: promote the effective use of technology for learning and ensure instructional innovation

- Excellence in professional practice: allocate time, resources and on-going professional growth in technology

- System improvement: lead purposeful change, recruit operational personnel, support system improvement and establish infrastructure for technology

- Digital citizenship: ensure equitable access, establish policies, model responsible social interactions and be involved in global issues (ISTE, 2009)

The NETS*A provides essential elements for school leaders as a guideline; it also helps them to be aware of vital issues when they use technologies in education settings. According to Sujo-Montes and Gallagher (2010), the elements in NETS*A indicate the essential parts for school leaders to focus on when they want to improve school with technologies.

\section{Research methods}

A qualitative approach was adopted in this study. An outstanding early childhood center was identified according to its rich learning resources in both digital technologies and non digital learning materials. In addition to the rich digital resources, this center is also awarded excellence in school performance among all the early childhood centers in the same educational organization.

The selected case is an early childhood centre located in New Territories, Hong Kong, with about two hundred young children. There are one principal, two head-teachers, and twenty-two staff serving in this centre. The principal earned a master degree and both head-teachers have bachelor degree in early childhood education. This centre has six classrooms and two large indoor play areas. Each classroom has installed two computers in a learning corner, and a LCD projector with a scroll down screen on one side of the walls. Among those six classrooms, two of them equipped with an interactive whiteboard. In addition, there are other digital teaching tools for teachers to borrow from the centre office, such as IPad, video camera and some electronic toys.

In-depth interview with the center leader and teachers was conducted with semi-structured interview questions. Observations in classroom activities were conducted by using both in-class visits and video recording. Document review collected information of using technologies from both paper and web documents. Thematic data analysis was applied to categorize the leadership strategies of introducing technologies implementation in early childhood setting. This study utilized the thematic analysis method according to Braun and Clarke [2]. This method consists of six steps: 1) familiarizing with data, 2) generating initial coding systems, 3) searching for patterns and thus, themes, 4) reviewing themes, 5) defining and naming themes, and 6) producing the report. This research follows carefully of each step to ensure reliability and validity of results and findings.

\section{Findings and Discussion}

Leader makes difference and has great influence in promoting technologies use in educational settings, especially with innovative change [5]. Without appropriate leadership strategies, the successful rate of technology implementation may be minimal. The following paragraphs discuss the strategies applied in the case. According to information collected from the center leader, teachers and document analysis in this case, four major leadership strategies were summarized as key ones: providing authentic support, encouraging active trial, leading practical practice and forming pro-digital culture in organization.

Providing authentic support. The center leader provides the necessary support for teachers according to their true needs. There are several channels for teachers to indicate and express their individual needs and expectation to top management. For example, use of digital applications - Whatsapp, Facetime, Skype; open door policy; monthly meetings; anonymous letter box; annual questionnaire etc. Teachers are welcomed to express their views on technology use and state their needs to the center leader. This shows the openness of the leader and willingness to communicate. Therefore, the center leader has good opportunity to understand individual needs of her staff, and she can plan to accommodate teachers' authentic needs in order to improve and support teachers' use of technologies. 
In addition to be a good listener and communicator, the center leader also supports teachers with time and money to consolidate their use of technologies. Teachers are encouraged to learn higher levels of computer skills by attending different technology workshops. All tuition fees are paid by the early childhood center as long as teachers successfully complete the whole course with certificate awarded. Teachers also get time off on Saturday mornings to prepare the digital learning and teaching materials. There are teaching and learning materials design competition every year, the center leader selects the top ten learning materials used by teachers during the year, five awards for digital materials and five for non-digital materials. Teachers appreciated the idea of competition, they indicated that the annual award motivate their innovative thoughts when they design their teaching materials. A K3 teacher asserts, "Whenever I design digital learning materials, I target to make them userfriendly, educational and practically meaningful. In this way, I can achieve those teaching goals, and I can also have chance to win the award" (T-K3-A).

Technical support is also one of the strengths in this center. The leader hires two staff with advance technical skills in order to support teachers with using technologies. These two special teachers also provide regular on-site technology training for other staff. Many teachers indicate that "these two technology supporting colleagues are the stimuli for them to use technologies. Whenever they need help, they can seek assistance from the technical staff, they are very helpful" (T-K2-A, T-K3-B, T-K2-B). One teacher stress that "The technical support staff are helpful, sometimes when I try on some new applications in class, they came into my classroom and provide me with in-class support, then I do not feel scary about using new technologies. This way, I feel more comfortable in making change" (T-K2-B).

Since there are sufficient supports for teachers to use technologies in this center, teachers are willing to use technologies with young children in various learning activities. Some examples are as follows: teachers organized field trip with children in the Wetland Park, children can use tablets to take photos for further sharing (see Figure 1), children are encouraged to draw what they have visited in the field trip (Figure 2), a pair of children learn with computer in a learning corner in the center (Figure 3).

Encouraging active trial. The center head believes that to learn technologies by doing it is the best method. She emphasize that "without taking risk of making mistakes, teachers may not want to try new technologies. As there are many new models and updated versions of technologies, teachers need to keep learning and try new machines, if not, there is no use for children's learning because teachers scare to try out". The center leader not only purchased new learning technologies (i.e., smart books, tablets), but also encourage teachers to bring home and try out. The centre leader states that "It is clearly noted in our teacher handbook about the facilities loan out policy. All staff is encouraged to loan the tablets or laptops during weekends. This is to encourage their on-going practice and trial out".

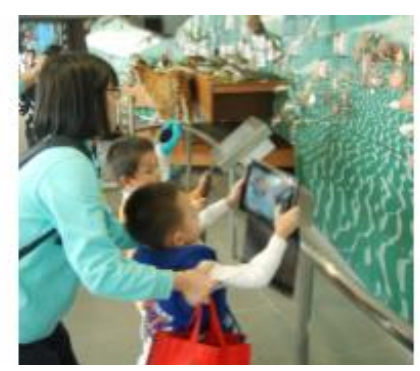

Figure 1. School visits the Wetland Park. Children used Tablet to take the photos

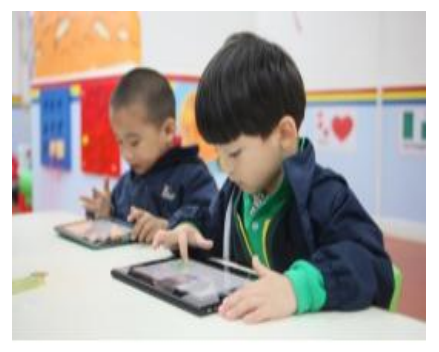

Figure 2. Children draw and share what they like after their field trip

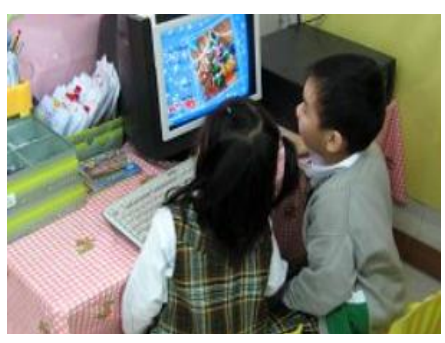

Figure 3. Children pair up and use computer in learning corner

Furthermore, the centre leader prefers to provide a brief workshop for all teachers whenever there are new technologies being purchased in the early childhood center. She made sure all teachers have chance to learn how to use those new technologies and get trail out experience. In addition to bring the device home for trial, the center leader also encourages teachers to try on different digital 
applications (Apps) or young children websites. The center leader said: "Teachers are funded with HK\$300 for purchasing suitable Apps in each semester, they can install appropriate Apps onto their own tablets or smart phone for teaching and learning purposes". In this way, teachers are encouraged and motivated to try new Apps and apply technologies in their classrooms.

Leading practical practices. The center leader acts as a modeler in using technologies to communicate with teachers and parents. Whenever there are important center notices for parents, the center leader uploads to school web and set up a forum for parents to seek assistance. The center leader arranged staff to upload school activities photos onto the school web regularly, she asserted that: "Parents love to view the photos of their own kids, they are interested to know more about their kids' behaviors or performance in school, with the consent of parents, there are regularly upload of school activities pictures on our school web page. I am sure this can encourage both my colleagues and parents to use the school web more frequently". Since the center leader leads the practice by doing, all teachers follow her role model. Furthermore, the center leader always purchase the new software and machines, she is the one willing to try new technologies, and share with her staff on what she discovered or learnt. Her own practices do influence other colleagues in certain ways.

Forming pro-digital culture in organization. To develop the positive organizational culture needs great efforts from both the leaders and staff [6]. In order to promote effective use of learning technologies in school, forming pro-digital culture is essential. If the staffs in an organization have positive perception on using technologies, they tend to willing to apply technologies in their works. On the contrary, if the staffs do not feel comfortable in using new technologies, they probably refuse to try. The centre leader in this case actively promote the technology implementation by being a role model, by purchasing suitable learning technologies and software, by arranging appropriate supports, by developing relevant policies. All these methods build the pro-digital culture in the centre steps by steps. According to the centre leader, many more teachers are willing to try to learn more about technologies for teaching and learning, "there were only small number of staff using computers before, but now, almost all staffs are capable to use technologies for teaching purpose".

\section{Conclusion}

These four leadership strategies motivate teachers to apply technologies actively in their classrooms with young children. The center leader plays an important role to make the technologies implementation successful in her early childhood center - give suitable support to teachers according to their needs, let teachers act on and try out instead of just watching others using technologies, be a role model to teachers, and reinforce actual hands on practices. It is impossible to talk about effective technology implementation without practical leadership strategies to motivate staff to apply technologies and make things happen. In this fastchanging world with abundant types of information and communication technology, early childhood leaders do need to be well equipped and prepared their colleagues and staffs to meet the technology challenges in the $21^{\text {st }}$ century.

\section{References}

[1] Anderson, R.E., \& Dexter, S.L. (2005). School technology leadership: An empirical investigation of prevalence and effect. Educational Administration Quarterly, 41, 49-82.

[2] Braun, V., \& Clarke, V. (2006). Using thematic analysis in psychology. Qualitative research in psychology. 3(2), 77-101.

[3] Creighton, T. (2003). The principal as technology leader. Thousand Oaks. CV: Corwin Press.

[4] Culp, K., Honey, M., \& Mandinach, E. (2005). A retrospective on twenty years of education technology policy. Journal of Educational Computing Research, 32(3), 279-307.

[5] Flanagan, L., \& Jacobsen, M. (2003). Technology leadership for the twenty-first century principal. Journal of Educational Administration, 41(2), 124-142.

[6] Fullan, M. (2008). The six secrets of change: What the best leaders do to help their organizations survive and thrive. San Francisco, CA: Jossey-Bass.

[7] Han, C. W. C. (2010). Sustaining leadership capability via media technologies: Towards social network perspective. Journal of Applied Computing, 6 (1). (In Portuguese)

[8] Han, C.W.C. (2002). Leadership Roles of a Preschool Principal in the use of ICT. Contemporary issues in Early Childhood, 3 (2), 293-297.

[9] Hong Kong Special Administrative Region. (2006). The 2006 Policy Address. HKSAR: Printing Department.

[10]International Society for Technology in Education (ISTE) (2009). National Educational Technology Standard for Administrators. Retrieved Aug 2014, from http://www.iste.org/standards/nets-foradministrators/nets-for-administrators-sandards.aspx

[11] Leung, W. M. (2010). Young children's learning with information and communication technologies in Hong Kong kindergartens. Doctoral dissertation. Retrieved November 15, 2013 from Australian Digital Theses Program. 
[12]Li, H. (2006). Integrating ICT into the early childhood curriculum: Chinese Principals' views of the Challenges and Opportunities. Early Education and Development, 17(3), 467-487.

[13] McKenzie, J. (2002). Leading by example: the high touch high tech principal. From Now On: The Educational Technology Journal, 11(10). Retrieved 30 May, 2014, http://www.fno.org/sum02/principal.html

[14] National Association for the Education of Young Children. (2012). Technology and interactive media as tools in early childhood programs serving children from birth through age 8. A position statement of NAEYC on Young children and technology. Retrieved September 9, 2014, http://issuu.com/naeyc/docs/ps_technology _issuu_may2012? mode $=$ window $\&$ backgroundColor $=\%$ 23222222

[15]Neufeld, D.J., Dong, L. \& Higgins, C. (2007). Charismatic leadership and user acceptance of information technology. European Journal of Information Systems, 16(4), 494-510.

[16]Schiller, J. (2003). Working with ICT perceptions of Australian principals. Journal of Educational Administration, 41(2), 171-185.

[17] Schmeltzer, T. (2001). Training administrators to be technology leaders. Technology and Learning, 21(11), 1622.

[18] Sugar, W. (2005). Instructional technologist as a coach: Impact of a situated professional development program on teachers' technology use. Journal of Technology and teacher education, 13(4), 547-571.

[19] Sujo-Montes, L. \& Gallagher, L. (2010). School, technology, and society home-school communications and access. In R. Papa (Ed.), Technology leadership for school improvement (pp. 167-188). London: Sage. 